\title{
Separation of Potent and Poorly Functional Human Lung Accessory Cells Based on Autofluorescence
}

\author{
Laurent P. Nicod, Mary F. Lipscomb, Galen B. Toews, and Jonathan C. Weissler \\ Departments of Internal Medicine (L.P.N., G.B.T., J.C.W.) and Pathology (M.F.L.), The University of Texas \\ Southwestern Medical Center at Dallas
}

\begin{abstract}
Human alveolar macrophages obtained by bronchoalveolar lavage are usually poor accessory cells in in vitro lymphoproliferation assays. However, we recently described a subpopulation of pulmonary mononuclear cells, obtained from minced and enzymedigested lung, which were potent stimulators of allogeneic T-lymphocyte prollferation. These cells were enriched in loosely adherent mononuclear cell (LAM) fractions, but further study of these accessory cells was hampered by the heterogeneous nature of LAM. It was observed that in the majority of lung tissue sections, most alveolar macrophages were autofiuorescent, whereas most interstitial HLA-DR positive cells were not. Therefore autofluorescence was utilized to fractionate LAM in an attempt to remove alveolar macrophages and selectively purify interstitial accessory cells. LAM were separated by flow cytometry using forward and side scatter to exclude lymphocytes, and red autofluorescence to obtain brightly autofluorescent (A pOs) and relatively nonautofluorescent (A neg) mononuclear cells. Although both populations contained over $80 \%$ HLA-DR positive cells, A pos cells were poor accessory cells, whereas A neg cells were extremely potent stimulators of a mixed leukocyte reaction at all stimulator ratios tested. When A pos cells were added to A neg cells, T-cell proliferation was markedly suppressed in the majority of experiments. Morphologically, A pos cells appeared similar to classical alveolar macrophages with $95 \%$ of the cells being large and intensely nonspeclfic esterase positive. In contrast, the majority of A neg were smaller, B-cell antigennegative, nonspecific esterase negative, and had a distinctive morphology on Wrightstained smears. We conclude that fractionation of LAM based on autofluorescence is a powerful tool to lsolate and characterize lung mononuclear cells that act elther as stimulators or as suppressors of immune responses in the lung.
\end{abstract}

Key words: pulmonary immunity, alveolar macrophages, dendritic cells

\section{INTRODUCTION}

The expression of an immune response in the lung may be essential to a host's capacity to clear infectious agents acquired via the respiratory tract. In addition, exaggerated or inappropriate cellular and/or humoral immune responses can result in lung diseases such as hypersensitivity pneumonitis [12] or sarcoidosis [6]. The initiation of most immune responses requires an interaction between accessory cells and $T$ lymphocytes. However, the majority of previous studies have demonstrated that human alveolar macrophages from bronchoalveolar lavage are usually poor accessory cells in in vitro lymphoproliferation assays $[9,30,32,33]$.

We recently demonstrated that a potent accessory cell could be obtained from minced and enzyme-digested human lung [18]. This accessory cell was enriched in the loosely adherent population of lung mononuclear cells
(LAM) and was significantly more efficient than alveolar macrophages in the stimulation of an allogeneic mixed leukocyte reaction (MLR). Although this accessory cell had properties (Fc receptor negative, poorly phagocytic) that suggested it was distinct from a classical macrophage, further attempts at characterizing this cell were

Received October 19, 1988; accepted December 7, 1988.

Laurent P. Nicod's current address is Department of Internal Medicine, Hopital Cantonal of Geneva, 1211 Geneva, Switzerland.

Galen B. Toews' current address is Division of Pulmonary and Critical Care Medicine, University of Michigan Medical Center, 3916 Taubman Center, Ann Arbor, MI 48109-0360.

Reprint requests: Jonathan C. Weissler, Department of Internal Medicine-Pulmonary Division, University of Texas Southwestern Medical Center, 5323 Harry Hines Blvd., Dallas, TX 75235-9034. 
hampered by the heterogeneous nature of LAM. Indeed, the heterogeneity of lung accessory cells had previously been noted by other investigators using cells from bronchoalveolar lavage $[4,25]$, and interpretation of in vitro assays has been complicated by the variability of alveolar macrophage-induced suppression of T-cell proliferation $[15,23]$. Thus, it was important to further enrich the cells with accessory cell function in LAM.

Although the anatomic location of the accessory cells in LAM remains unproven, previous studies [18,33] demonstrating accessory cell activity in digested lung specimens but not in bronchoalveolar lavage suggested that at least the majority of accessory cells were in the interstitium. We observed that in the majority of lung tissues examined, most alveolar macrophages were brightly autofluorescent, whereas most interstitial HLADR positive cells were not. Utilizing the fluorescenceactivated cell sorter (FACS), LAM were fractionated into brightly autofluorescent (A pos) and relatively nonautofluorescent (A neg) populations. A pos cells were larger with the morphology of classical alveolar macrophages and were poor stimulators of an MLR. Conversely, A neg cells were predominantly nonspecific esterase negative and were extremely potent stimulators of an MLR compared to both LAM and A pos cells. Mixing experiments demonstrated that A pos suppressed allogeneic T-cell proliferation induced by $\mathbf{A}$ neg cells. These results demonstrate that autofluorescence can be used to separate lung mononuclear cells into populations with divergent effects on T-cell stimulation. More importantly, the data demonstrate that potent accessory cells, largely distinct from classical macrophages, are present in human lung parenchyma.

\section{MATERIALS AND METHODS}

\section{Human Subjects}

Grossly normal pulmonary tissue was obtained from surgical specimens resected from patients with primary lung carcinoma and from subjects autopsied within $6 \mathrm{hr}$ of a sudden death. All surgical patients were smokers but the smoking history for forensic subjects could not be obtained. No patient had clinical or pathological evidence of active pulmonary infection at the time of collection of the specimen.

Preparation of cells from lung. Pulmonary mononuclear cells were obtained from whole lung by mincing and enzyme digestion as previously described [18]. Briefly, lung specimens were rinsed with Hanks' balanced salt solution (HBSS) to remove residual blood. The tissue was minced and lung fragments digested with type I collagenase $(150 \mathrm{U} / \mathrm{ml})$ and type IIA elastase (10 $\mathrm{U} / \mathrm{ml}$, both from Sigma Chemical Co., St. Louis, MO). The enzyme-digested lung was tapped through a stain- less steel screen and separated on a Ficoll-Hypaque density gradient of $1.079 \mathrm{gm} / \mathrm{dl}$ (Ficoll from Sigma Chemical Co., St. Louis, MO; Hypaque from WinthropBrean, New York, NY). Viability as assessed by trypan blue was $>90 \%$. Differential counts were performed on Wright-stained smears; 70-75\% were large, macrophage-like; $20-25 \%$ were typical lymphocytes.

Loosely adherent mononuclear cells (LAM) were obtained from pulmonary mononuclear cells according to the method of Van Voorhis et al. [31]. Briefly 150-350 $\times 10^{6}$ cells were incubated in complete medium containing $10 \%$ heat-inactivated fetal calf serum (FCS) on $100 \mathrm{~mm}$ tissue culture dishes in aliquots of $20-25 \times 10^{6}$ cells/dish at $37^{\circ} \mathrm{C}$. The nonadherent cells were removed after $1 \mathrm{hr}$ using three vigorous rinses of HBSS. Nonadherent cells represented half of the pulmonary mononuclear cells; $30-40 \%$ were lymphocytes, $10-20 \%$ were unidentifiable cells, and the remaining cells were macrophage-like as determined on Wright-stained cytocentrifuge smears. The adherent cells were incubated for an additional $14-16 \mathrm{hr}$ at $37^{\circ} \mathrm{C}$ in complete medium (RPMI) with $10 \%$ FCS. The cells that spontaneously released plus cells dislodged with three gentle rinses with HBSS are referred to as LAM.

Cell analysis and sorting. Unstained LAM were analyzed and sorted with a FACSTAR (Becton-Dickinson) equipped with a Innova coherent 90 laser. Data were processed on a Consort 30/HP310 computer system. Cell size and internal complexity were analyzed based on forward and $90^{\circ}$ scatter, respectively. Thus, $70-80 \%$ of the total cells that were the size of monocytes or macrophages were in the gates, and lymphocytes and dead cells were excluded (Fig. 1A). Autofluorescence was analyzed using an excitation wavelength of $488 \mathrm{~nm}$ and emissions measured using a $585 \mathrm{~nm}$ filter. The upper threshold chosen for the autofluorescent negative cells was set at the first inflexion of the curve plotting the number of cells vs autofluorescence and included an average of $12-20 \%$ of the gated population (Fig. 1B).

Preparation of responder peripheral blood $T$ lymphocytes. Peripheral blood mononuclear cells from normal volunteers were obtained on a Ficoll-Hypaque gradient, washed $3 \times$ in HBSS, and purified as previously described [14]. Briefly, after adhesion on plastic culture dishes, nonadherent cells were removed by washing. Lymphocytes were further depleted of accessory cells with $5.0 \mathrm{mM}$ L-leucine methyl ester, T cells rosetted with 2 aminoethylisothiouronium bromide-treated sheep red blood cells (SRBC) at $4^{\circ} \mathrm{C}$, followed by sedimentation through Ficoll-Hypaque, and, after lysis of SRBC with $0.15 \mathrm{M} \mathrm{NH} \mathrm{NCl}_{4}$, the lymphocytes were passed through a nylon wool column. Lastly, $T$ cells were treated with anti-HLA-DR (L243) and baby rabbit complement. 


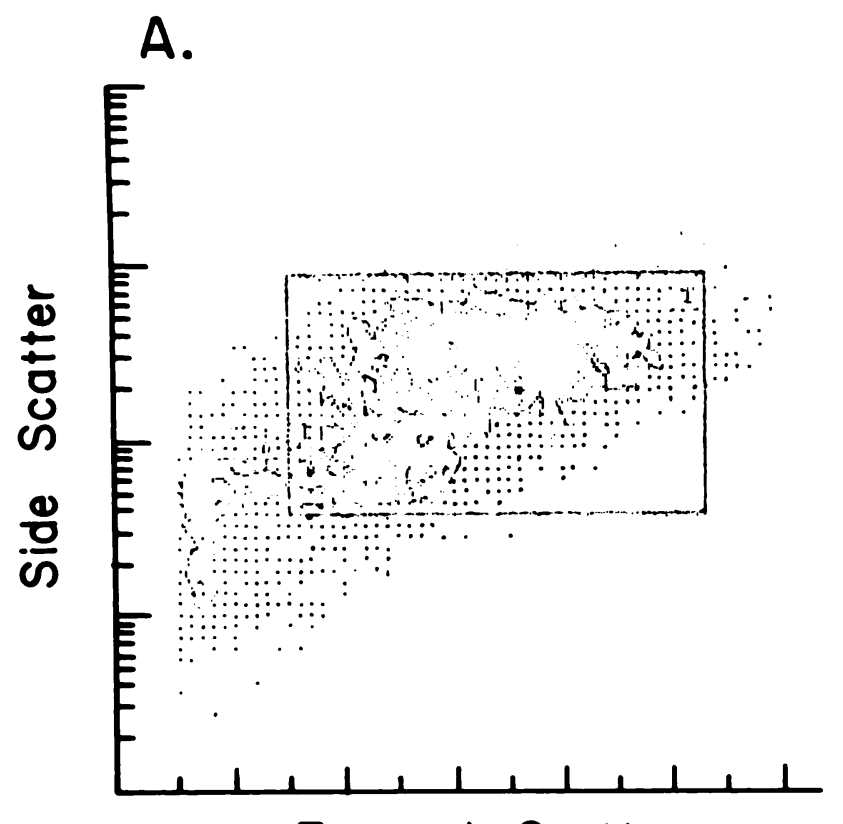

Forward Scatter

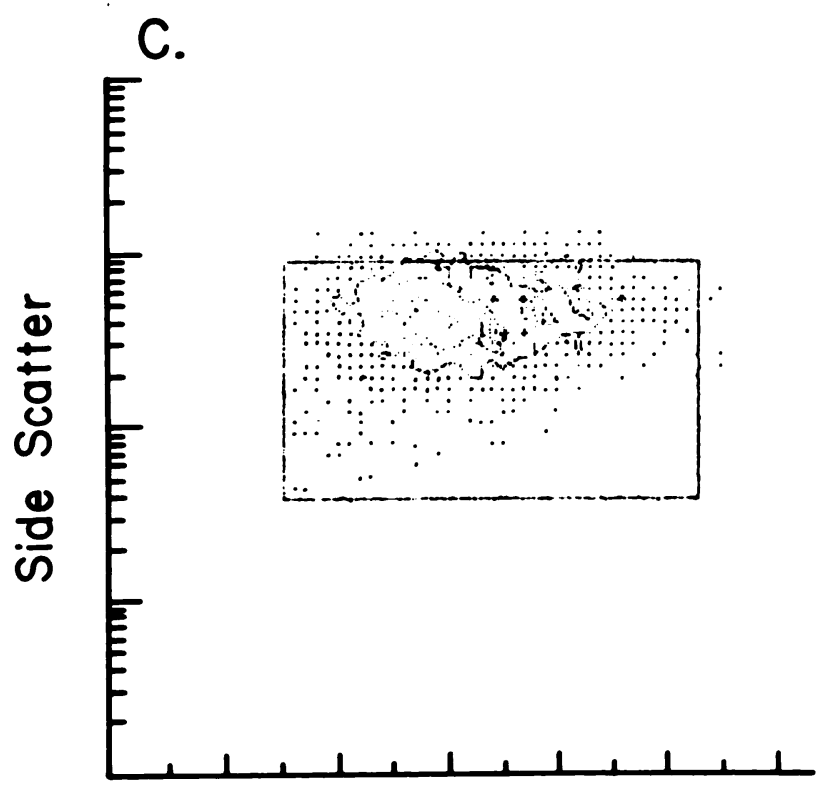

Forward Scatter

Fig. 1. Flow cytometric characteristics of LAM, A neg, and A pos. Size (forward scatter) and internal complexity (side scatter) of the LAM population are shown with gates set to exclude dead cells and lymphocytes (bolow and to the left of the left comer of

Mixed leukocyte reaction (MLR). LAM, A neg and A pos cells were irradiated $(4,500$ rads) in a cesium source. Various numbers of accessory cells were incubated with purified allogeneic T cells $\left(10^{5}\right)$ in $200 \mu$ l medium containing $20 \%$ human serum in flat-bottomed microtiter plates in triplicate or quadruplicate for 6 days
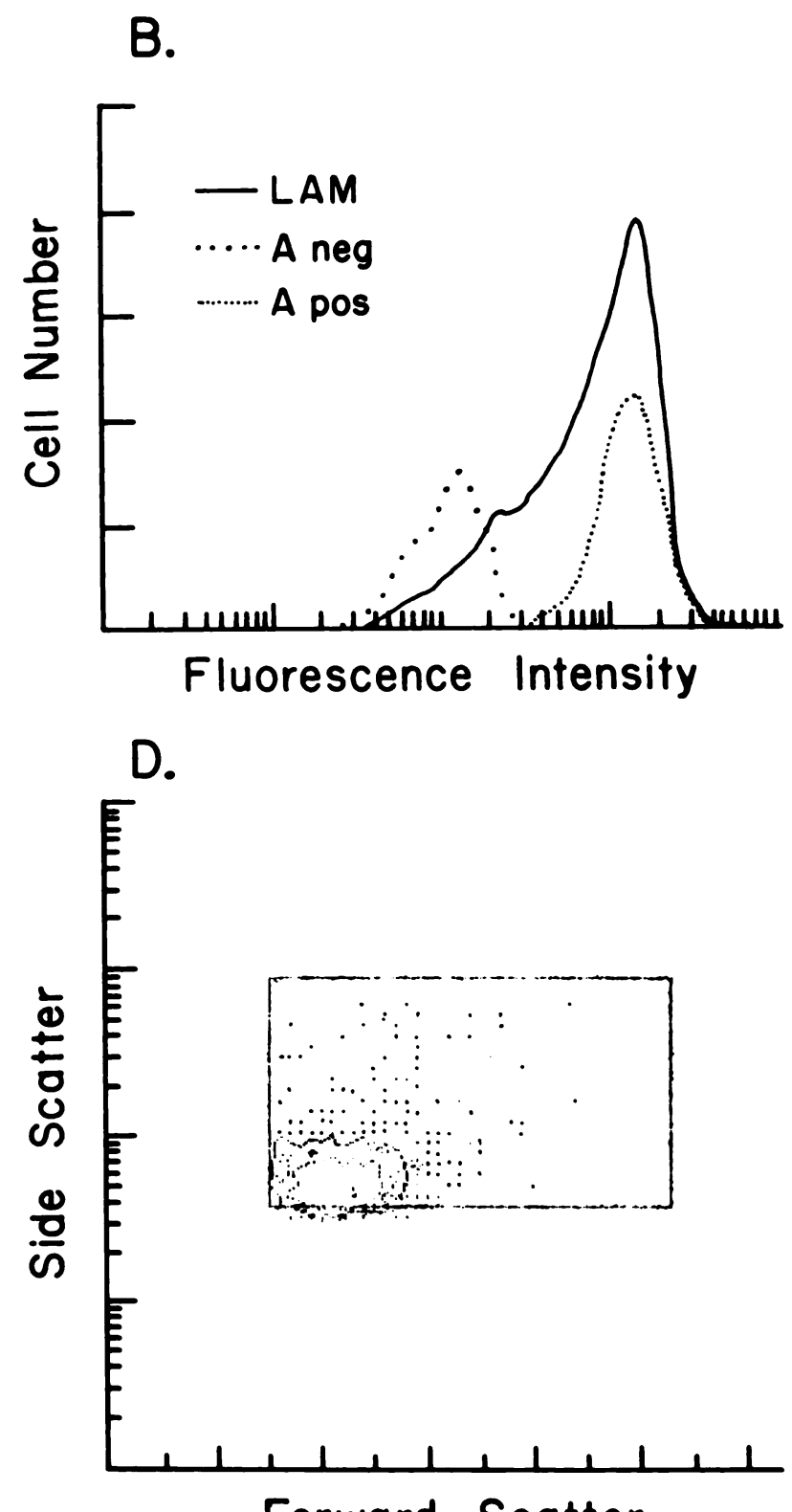

the rectangle) (A); fluorescence intensity of the three populations (B); size and cellular complexity of A pos cells (C), and A neg cells (D) in a postsort analysis.

at $37^{\circ} \mathrm{C}$ in $95 \%$ air $/ 5 \% \mathrm{CO}_{2}$. Cultures were treated with $0.5 \mu \mathrm{Ci}\left[{ }^{3} \mathrm{H}\right]$ thymidine $\left({ }^{3} \mathrm{HThy}, 5.0 \mathrm{Ci} / \mathrm{mmol}\right.$; Amersham Corp., Amersham, UK) $18 \mathrm{hr}$ prior to harvest, collected with an automated cell harvester, and analyzed in a liquid scintillation counter. Data were expressed in counts per minute. 


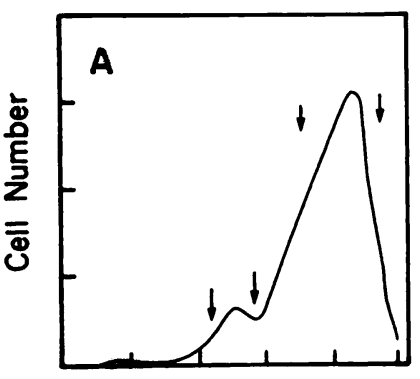

Fluorescence Intensity

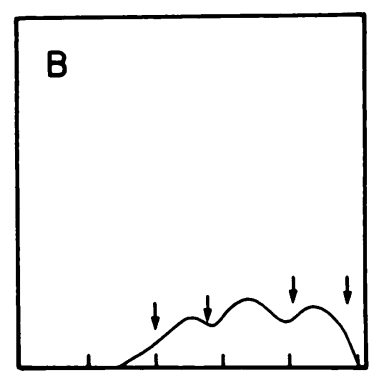

Fluorescence Intensity
Fig. 2. Precort analysis of LAM revealed two major patterns of autoflucrescence. The most common pattern revealed two populations (A), while occasionally three populations (B), were obeenved. In each histogram the left set of arrows denotes the markers used to select A neg cells, while the right set of arrows denoties the selection of A pos cells. Histograms have been electronleally smoothed.

Morphologic and phenotypic analysis. Cytocentrifuge smear preparations were Wright stained or tested for nonspecific esterase activity according to the method of Yam et al. [34] with an incubation time of $30 \mathrm{~min}$. In our hands, $30 \mathrm{~min}$ of incubation stained the majority of monocytes strongly positive and alveolar macrophages intensely positive. Phenotypes were studied utilizing indirect immunofluorescence on cytocentrifuge smears. Mouse monoclonal antibodies used were L243 (anti HLA-DR) from the cell line 243 originally described by Lampson and Levy [11], BA (anti-B-lymphocyte) from Hybritech, Inc., San Diego, CA, $\mathrm{MO}_{2}$ (antimonocyte) kindly provided by Dr. P.E. Lipsky (UTHSC at Dallas), and a control mouse IgG monoclonal antibody.

\section{RESULTS}

\section{Isolation of Lung Mononuclear Cells by Autofluorescence}

Flow cytometry was previously utilized to characterize alveolar macrophages based on autofluorescence in rodents [13]. The method was attractive as a method for subfractionating LAM obtained from human lung since the autofluorescence of human alveolar macrophages is well known. In addition, cells could also be characterized according to their size (forward scatter) and internal complexity (side scatter). LAM were analyzed by setting gates to exclude dead cells and lymphocytes (Fig. 1A) and studied for red autofluorescence. Although all cells within the gates had some degree of autofluorescence relative to lymphocytes, a distinct population of relatively nonautofluorescent (A neg) cells was generally clearly apparent from a "shoulder" on the histogram (Fig. 2A). In the majority of experiments the histogram revealed two populations although occasionally three populations were identified (Fig. 2B). A neg cells were obtained from the cell sorter by selecting for the least autofluorescent cells. Brightly autofluorescent cells (A pos) were obtained from the most autofluorescent cells in the LAM population. A neg cells constituted from 12 to $20 \%$ of the gated LAM whereas A pos cells usually constituted $60-65 \%$ of gated cells. Cells with an intermediate level of fluorescence were discarded by the FACS.

Following the cell-sorting procedure, a postsort analysis revealed A neg and A pos populations with less than $1 \%$ overlap (Fig. 1B). Analysis of the A pos cells and A neg cells revealed that $A$ neg had less forward and side scatter than A pos with minimal overlap (Fig. 1C). Cells obtained by sorting were $>95 \%$ viable by trypan blue exclusion.

Morphology of $A$ neg and $A$ pos cells. When compared to unfractionated LAM, a difference in the morphology of A neg cells was apparent. Wright stains of the LAM population showed the majority of cells to be similar to alveolar macrophages (Fig. 3a). The A pos cells had the appearance of large macrophages usually with intracellular inclusions of carbon and/or hemosiderin pigment (Fig. 3b). The A neg cells were smaller, had few cytoplasmic inclusions, and the majority of cells had a characteristic convoluted nucleus (Fig. 3c). Many of the cells demonstrated a perinuclear clear zone.

Nonspecific esterase (NSE) is an enzyme present in the majority of monocytes or monocyte-derived macrophages. NSE staining of the populations revealed that $95 \%$ of the A pos cells were NSE positive, whereas only $29 \%$ of the A neg cells contained NSE (Table 1). Comparable staining times for peripheral blood monocytes revealed definite staining of these cells. Thus, the majority of A neg cells were not classical macrophages.

To function as an accessory cell, Class II major histocompatibility antigens must be expressed on the cell surface [5]. Analysis of the populations by immunofluorescent staining revealed that the majority of cells in LAM, A neg, and A pos populations expressed HLA-DR and thus had the potential to function as accessory cells (Table 1). Because B cells are capable of acting as accessory cells [7], the presence of $B$ cells was determined. No B cells were present in the A neg population. Although NSE staining had suggested that the majority of A neg cells were not macrophages, the smaller size of A neg cells made it important to determine the relative frequency of monocytes in the three populations. Staining for $\mathrm{MO}_{2}$, a marker present on the majority of peripheral blood monocytes [33], revealed that contamination of the $\mathrm{A}$ neg population by monocytes was minimal and was no different from the A pos cells. Thus, A neg cells were morphologically distinct from both $A$ pos and unfractionated LAM and were composed pre- 

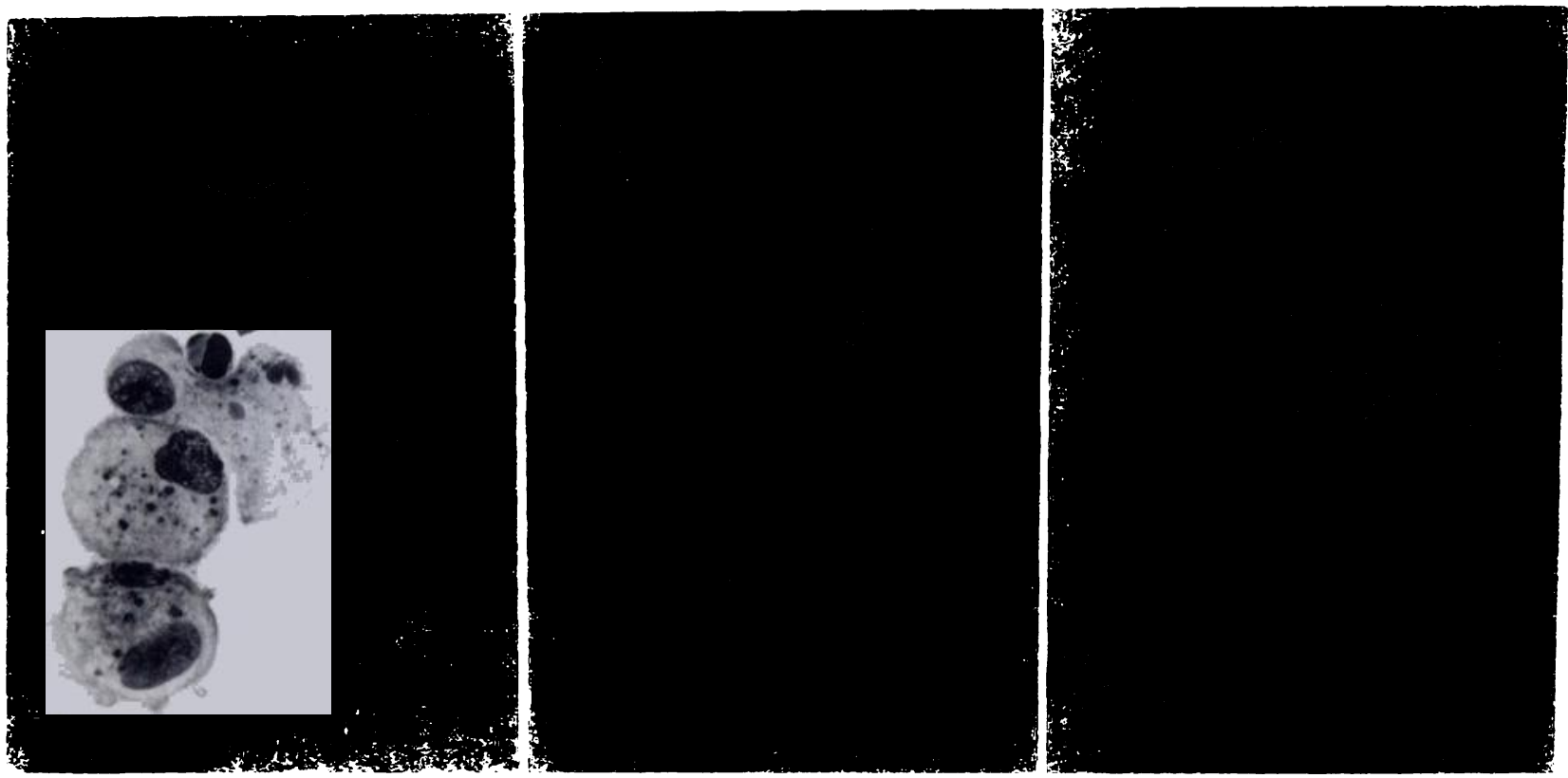

Fig. 3. Wright stain of cytocentrifuge preparations of LAM (a), A pos cells (b), and A neg cells (c). A neg cells were smaller and had a characteristic convoluted nucleus $(\times 320)$.

TABLE 1. Phenotypic Comparison of Cells Obtained in LAM, A neg, and A pos Populations"

\begin{tabular}{lccc}
\hline & LAM & A neg & A pos \\
\hline $\begin{array}{l}\text { Nonspecific esterase } \\
\text { positive }\end{array}$ & & & \\
HLA-DR $^{\mathrm{c}}$ & $76 \pm 3$ & $29 \pm 1$ & $96 \pm 2$ \\
$\mathrm{BA}_{1}{ }^{\mathrm{c}}$ (B cells) & $82 \pm 2$ & $80 \pm 7$ & $88 \pm 0$ \\
$\mathrm{MO}_{2}{ }^{\mathrm{c}}$ (monocytes) & $<1 \%$ & $<1 \%$ & $<1 \%$ \\
\hline
\end{tabular}

$\mathrm{a}_{n}=3$.

${ }^{b}$ Cytocentrifuge smears were stained for nonspecific esterase. The percentage of positive cells among all cells is indicated.

cCells were stained by indirect immunofluorescence and evaluated by fluorescence microscopy. Results are expressed as percentage positive cells above control.

dominantly of HLA-DR positive cells other than classical macrophages.

Accessory cell function of LAM, A pos, and A neg cells. The accessory cell function of LAM, A pos, and A neg cells was compared utilizing an allogeneic MLR. We had previously shown that LAM were significantly more potent than alveolar macrophages obtained from bronchoalveolar lavage in the stimulation of a MLR [18]. In preliminary experiments over a range of stimulator: responder ratios, LAM were efficient stimulators of allogeneic T-cell proliferation (Fig. 4). However, A neg cells were significantly more potent than an equivalent number of LAM. Indeed, since approximately 15-20\% of LAM were A neg cells the dose-response curve suggested that virtually all of the accessory cell function of LAM was confined to the A neg population. In

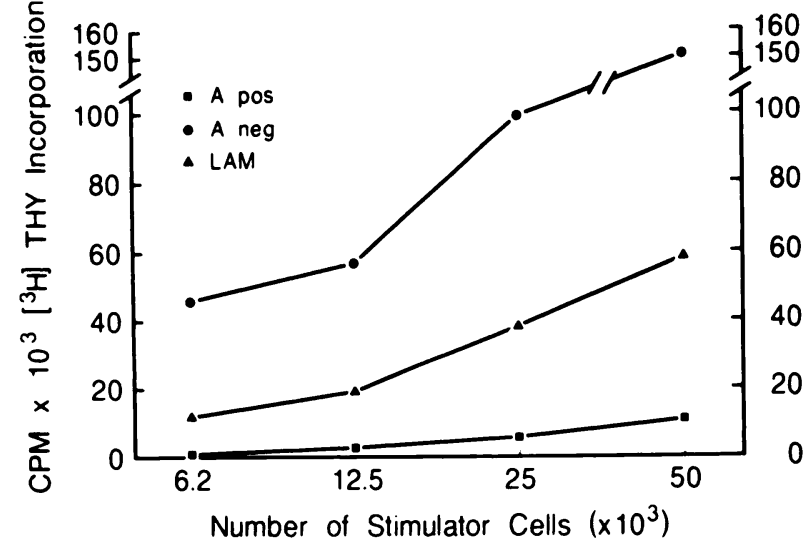

Fig. 4. Comparison of LAM, A pos and A neg cells in the stimulation of an allogeneic MLR. Allogeneic $T$ cells $\left(10^{5}\right)$ were incubated with increasing numbers of accessory cells for 6 days and T proliferation determined by [ $\left.{ }^{3} \mathrm{H}\right]$ thymidine incorporation. A representative experiment is shown. Standard deviation of quadruplicate cultures was $<5 \%$.

contrast, A pos cells were poor accessory cells at all stimulator ratios tested.

Utilizing seven separate populations of lung LAM, A neg cells were significantly more potent accessory cells than LAM (Fig. 5). Conversely, A pos cells were significantly poorer accessory cells than LAM. Thus separation of LAM into relatively nonautofluorescent and brightly autofluorescent populations obtained lung mononuclear cells with either potent or poor accessory cell function. 


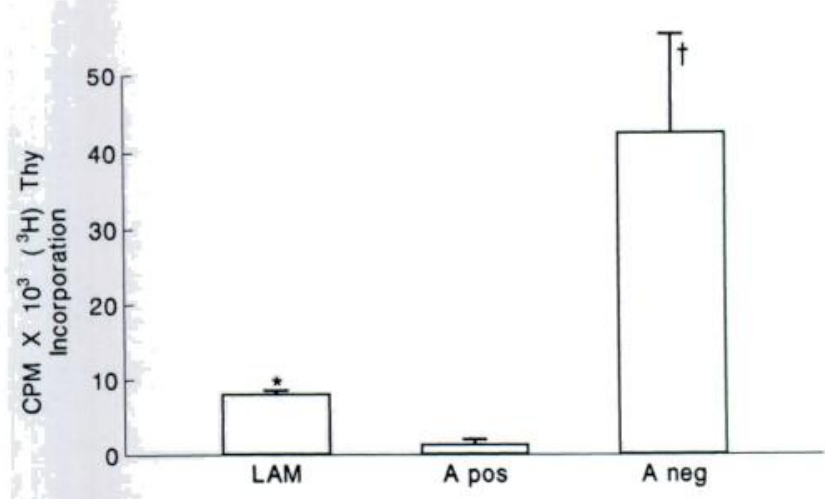

Fig. 5. Comparison of LAM, A pos, and A neg cells in the stimulation of an allogeneic MLR. Results are shown using 12.5 $\times 10^{3}$ accessory cells and $10^{5} \mathrm{~T}$ cells. Similar results were obtained at other stimulator ratios. ${ }^{*} p<.001$ compared to A pos cells, ${ }^{\dagger} \boldsymbol{p}<.001$ compared to LAM. $n=7$.

Suppression of $\mathbf{T}$ proliferation by A pos cells. One possibility suggested by the results was that the intermediate efficiency of LAM could be partly explained by suppression of A neg cells by A pos cells. Therefore, mixing experiments were performed (Table 2). When A pos:A neg ratios of 2:1 or greater were studied, significant suppression of the MLR occurred in the majority of experiments.

\section{DISCUSSION}

In the current study we utilized autofluorescence to fractionate loosely adherent human lung mononuclear cells into relatively nonautofluorescent and brightly autofluorescent subpopulations. The subpopulations were compared to the parent LAM in their ability to induce allogeneic T-lymphocyte proliferation. The major findings were (1) A neg cells were extremely potent accessory cells compared to unfractionated LAM and A pos cells. (2) In contrast to both LAM and A pos cells, A neg cells were predominantly nonspecific esterase negative and smaller than the majority of alveolar macrophages. (3) A pos cells were poor accessory cells compared to LAM and suppressed the T proliferation induced by $\mathbf{A}$ neg cells. Thus, the fractionation of lung mononuclear cells by autofluorescence resulted in two populations with distinct immunoregulatory properties.

Autofluorescence has been noted in the alveolar macrophages of several animal species including man [20]. Although the precise biochemical mechanism for autofluorescence is unknown and may vary at different wavelengths, metabolic changes including reduced nicotinamide coenzymes and flavoproteins have been described in cells that exhibit autofluorescence [22,26,27]. The utilization of autofluorescence to obtain subpopulations of lung mononuclear cells with differing metabolic
TABLE 2. Suppression of T-Cell Prollferation by A pos Cells"

\begin{tabular}{lccccc}
\hline Experiment & $\begin{array}{c}\text { T } \\
\text { only }\end{array}$ & $\begin{array}{c}\text { T }+ \\
\text { A pos }\end{array}$ & $\begin{array}{c}\text { T }+ \\
\text { A neg }\end{array}$ & $\begin{array}{c}\text { T + A pos } \\
\text { + A neg }\end{array}$ & $\begin{array}{c}\text { Suppression } \\
\text { (\%) }\end{array}$ \\
\hline 1 & 49 & 3,028 & 56,816 & 12,844 & 73 \\
2 & 391 & 685 & 67,199 & 196 & 97 \\
3 & 1,403 & 985 & 22,860 & 18,016 & 21 \\
4 & 1,464 & 1,597 & 30,694 & 8,154 & 73 \\
Mean & 827 & 1,574 & 44,392 & 9,802 & 66 \\
\pm SEM & \pm 412 & \pm 601 & $\pm 12,137$ & $\pm 4,368$ & \\
\hline
\end{tabular}

allogeneic T cells $\left(10^{5}\right)$ were cultured with $12.5 \times 10^{3}$ accessory cells. Results are expressed as cpm of $\left[{ }^{3} \mathrm{H}\right]$ thymidine incorporation after 6 days of culture. Mixing experiments utilized $12.5 \times 10^{3} \mathrm{~A}$ neg cells plus $25 \times 10^{3} \mathrm{~A}$ pos cells. LAM, A pos, and A neg cells alone incorporated $<680 \mathrm{cpm}$.

and functional characteristics has been appreciated by several other investigators $[21,23,24]$. Lehnert and colleagues fractionated rat alveolar macrophages into morphologically distinct subpopulations based on cytofluorographic properties [13]. In a more recent study, autofluorescence was used to differentiate among blood monocytes, alveolar macrophages, and interstitial macrophages [3].

The heterogeneity of accessory cells obtained by bronchoalveolar lavage had been noted by several previous investigators who utilized density gradients to study accessory cell subpopulations from rats and man $[4,25]$. In previous studies from our laboratory a potent accessory cell was obtained from human lung parenchyma that was not apparent in bronchoalveolar lavages [33]. Circumstantial evidence suggested that this accessory cell was not a classical macrophage: the cell was enriched in loosely adherent populations, was poorly phagocytic, and appeared to be Fc receptor negative [18]. However, overall the LAM population could not be distinguished morphologically from alveolar macrophages, and a method was sought to enrich for the potent accessory cell. Initially Percoll gradients were used to fractionate LAM. Although accessory cell function was enhanced in denser subpopulations, the subpopulations defined by density remained morphologically heterogeneous.

It was hoped that the A neg population would consist predominantly of interstitial cells. Indeed a recent study demonstrated that interstitial macrophages, as compared to alveolar macrophages, were less autofluorescent [3]. However, the exact anatomic location of our A neg cells is unproven. Preliminary studies have suggested that less than $1-2 \%$ of unfractionated bronchoalveolar lavage have cytofluorographic properties consistent with the A neg cells. Thus A neg cells may be present in normal bronchoalveolar lavage though they appear to be rare. Our results suggest the relatively poor accessory cell function of bronchoalveolar lavage cells may reflect 
suppression of the relatively rare A neg cells by large numbers of $A$ pos macrophages present in lavage.

The identity of the A neg cells is uncertain. We previously determined LAM did not contain B cells, Langerhans cells, or endothelial cells [18]. In the current study, it is apparent that A neg cells contain few monocytes, typical macrophages, or B cells. Although dendritic cells have many of the properties of $A$ neg cells [28,31], further characterization of the A neg population will be required before the relationship of dendritic cells and A neg cells is clear. This is a difficult problem since there is no specific marker for human dendritic cells. Another problem is that Ia positive, dendritic cells with potent accessory cell function appear to have different surface markers depending on their anatomic location. For example, murine Langerhans cells from the skin were Fc receptor positive, bore the macrophage antigen F4/80, and demonstrated Birbeck granules and NSE [23]. These properties were all rapidly lost in culture and the cell acquired the phenotype of mature splenic dendritic cells and became more potent accessory cells. In mouse lungs, NSE negative, Ia positive tracheal epithelial dendritic cells which were potent accessory cells were $\mathrm{Fc}$ receptor and Mac/positive in contrast to splenic dendritic cells which do not bear either of these markers [24].

Thus, it is quite possible that HLA-DR positive dendritic cells in the lungs of man may not bear the same phenotypic markers of those described in the peripheral blood of man [19]. Nevertheless, the Wright stain morphology of our lung cells is remarkably similar to a distinctive NSE negative dendritic cell isolated from human peripheral blood by Rasanen and co-workers who describe their cells as having the appearance of small monocytes, but with more basophilic cytoplasm and a perinuclear clear area [19]. Our cells demonstrated a more convoluted nucleus than the dendritic cells of this group, a feature not typical of peripheral blood monocytes.

The role of the pulmonary interstitium as a primary site for the generation of an immune response is controversial. Under normal circumstances, hilar lymph nodes are likely the predominant organ involved in primary immune responses to inhaled or aspirated foreign antigens [10]. However, accessory cells located in the interstitium may play an important role in the initiation of secondary immune responses against pathogenic organisms $[8,17]$. The involvement of the pulmonary interstitium in diseases characterized by an expansion of lymphocytes in the lung, such as sarcoidosis or hypersensitivity pneumonitis, also suggests that immune responses can occur in lung parenchyma $[6,12]$. The current study suggests that alterations in the quantitative and anatomic relationships between $A$ neg and $A$ pos cells could be involved in immune-mediated lung disease. Studies with cells from bronchoalveolar lavage using the cytofluorographic techniques described in this report may be valuable in understanding the pathogenesis of these diseases.

The relative homogeneity of the A neg and A pos populations provides the opportunity to disect the regulation of immune responses in human lung. The ability of A neg cells to produce cytokines such as interleukin-1 may be important in understanding the function of these cells and is a promising area of investigation. Indeed the enhanced stimulation of the MLR by A neg cells could result from increased release of IL-1 by the A neg population. Conversely, the mechanisms responsible for the poor accessory cell function of A pos cells and alveolar macrophages [16] merit further study. Both the mechanism of suppression by $A$ pos cells and the target of suppression (i.e., A neg cells, T cells, or both) remain to be determined. In addition, the ability of A neg cells to function as accessory cells for antigen-induced lymphoproliferation remains to be established.

In summary, fractionation of human lung mononuclear cells based on autofluorescence obtains populations of cells with divergent effects on T-cell responses. Application of this technique should prove useful in understanding the regulation of immune processes in human lung.

\section{ACKNOWLEDGMENTS}

The writers wish to acknowledge the cooperation of the Department of Anesthesiology, the Division of Thoracic Surgery, and the Department of Forensic Pathology at the University of Texas Southwestern Medical Center at Dallas. They also express their deep appreciation to Robert Tompkins and Helen J. Price for their technical assistance and to Pattie Pipes for her skillful preparation of the manuscript. This work was supported by National Institutes of Health Grants HL 29543, AI 21951, HL 01797, and M01 RR00633.

Jonathan C. Weissler is recipient of Clinical Investigator Award HL 01797 and a grant from the American Lung Association of Texas.

\section{REFERENCES}

1. Aubin, J.E. Autofluorescence of viable cultured mammalian cells. J. Histochem. Cytochem. 27,36,1979.

2. Benson, R.C., Meyer, R.A., Zoruba, M.E., and McKhann, G.M. Cellular autofluorescence-is it due to flavins? J. Histochem. Cytochem. 27,44,1979.

3. Dethloff, L.A., and Lehnert, B.A. Pulmonary interstitial macrophages: Isolation and flow cytometric comparisons with alveolar 
macrophages and blood monocytes. J. Leukocyte Biol. 43, 80,1988 .

4. Ferro, T.J., Kern, J.A., Elias, J.A., Kanroun, M., Daniel, R.P., and Rossman, M.D. Alveolar macrophages, blood monocytes, and density-fractionated alveolar macrophages differ in their ability to promote lymphocyte proliferation to mitogen and antigen. Am. Rev. Respir. Dis. 135,682,1987.

5. Finnegan, A., Neddleman, B.W., and Hodes, R.J. Antigen processing requirements for $T$ cell activation: Differential requirements for presentation of soluble conventional antigen vs cell surface MHC determinants. J. Immunol. 134,2960,1985.

6. Hunninghake, G.W., Garret, K.C., Richerson, H.B., Fantone, J.C., Ward, P.A., Rennard, S.I., Bitterman, P.B., and Crystal, R.G. Pathogenesis of the granulomatous lung diseases. Am. Rev. Respir. Dis. 130,476,1984.

7. Inaba, K., Koide, S., and Steinman, R.M. Properties of memory T lymphocytes isolated from the mixed leukocyte reaction. Proc. Natl. Acad. Sci. U.S.A. 82,7686,1985.

8. Jones, P.D., and Ada, G.L. Influenza virus-specific antibodysecreting cells in the murine lung during primary influenza virus infection. J. Virol. 60,614,1986.

9. Kaltreider, H.B., Caldwell, S.L., and Byrd, P.K. The capacity of normal murine alveolar macrophages to function as antigenpresenting cells for the initiation of primary antibody-forming cell responses to sheep erythrocytes in vitro. Am. Rev. Respir. Dis. $133,1097,1986$

10. Kaltreider, H.B., Curtis, J.L., and Arraj, S.M. The mechanism of appearance of specific antibody forming cells in lungs of inbred mice after immunization with sheep erythrocytes intratracheally. II. Dose-dependence and kinetics of appearance of antibody forming cells in hilar lymph nodes and lungs of unprimed and primed mice. Am. Rev. Respir. Dis. 135,87,1987.

11. Lampson, L.A., and Levy, R. Two populations of la-like molecules on a human B cell line. J. Immunol. 125,293,1980.

12. Leatherman, J.W., Michael, A.F., Schwartz, B.A., and Hoidal, J.R. Lung T cell in hypersensitivity pneumonitis. Ann. Int. Med. $100,390,1984$.

13. Lehnert, B.E., Valdezm Y.E., Fillak, D.A., Steinkamp, J.A., and Stewart, C.C. Flow cytometric characterization of alveolar macrophages. J. Leukocyte Biol. 39,285,1986.

14. Lipscomb, M.F., Lyons, C.R., Nunez, G., Ball, E.J., Stastny, P., Vial, W., Lem, V., Weissler, J., Miller, L.M., and Toews, G.B. Human alveolar macrophages: HLA-DR positive macrophages that are poor stimulators of a primary mixed leukocyte reaction. J. Immunol. 136,497,1986

15. Liu, M.C., Proud, D., Schleimer, R.P., and Plaut, M. Human lung macrophages enhance and inhibit lymphocyte proliferation. J. Immunol. 132,2895,1984.

16. Lyons, C.R., Ball, E.J., Toews, G.B., Weissler, J.C., Stastny, P., and Lipscomb, M.F. Inability of human alveolar macrophages to stimulate resting $\mathrm{T}$ cells correlates with decreased antigen specific T cell-macrophage binding. J. Immunol. 137,1173,1986.

17. Mason, M.J., Bice, D.E., and Muggenburg, B.A. Local pulmonary immune responsiveness after multiple antigenic exposures in the cynomolgus monkey. Am. Rev. Respir. Dis. 132,657,1985.

18. Nicod, L.P., Lipscomb, M.F., Weissler, J.C., Lyons, C.R.,
Albertson, J., and Toews, G.B. Mononuclear cells in human lung parenchyma: Characterization of a potent accessory cell not obtained by bronchoalveolar lavage. Am. Rev. Respir. Dis. 136,818,1987.

19. Rasanen, L., Lehto, M., and Leinikki, P. Enrichment of dendritic cells from human peripheral blood. J. Leukocyte Biol. 43, 343,1988 .

20. Reiter, C. Fluorescence test to identify deep smokers. Forensic Sci. Int. 31,21,1986.

21. Rich, E.A., Tweardy, D., Fujiwara, H., and Ellner, J.J. Spectrum of immunoregulatory functions and properties of human alveolar macrophages. Am. Rev. Respir. Dis. 136,258,1987.

22. Roque, A.L., and Pickren, J.W. Enzymatic changes in fluorescent alveolar macrophages of the lungs of cigarette smokers. Acta Cytol. 12,420,1968.

23. Schuler, G., and Steinman, R.M. Murine epidermal Langerhans cells mature into potent immunostimulatory dendritic cells in vitro. J. Exp. Med. 161,526,1985.

24. Sertl, K., Takemura, T., Tschachler, E., Ferrans, V.J., Kaliner, M.A., and Shevach, E.M. Dendritic cells with antigen-presenting capability reside in airway epithelium, lung parenchyma, and visceral pleura. J. Exp. Med. 163,436,1986.

25. Shellito, J., and Kaltreider, H.B. Heterogeneity of immunologic function among subfractions of normal rat alveolar macrophages. Am. Rev. Respir. Dis. 129,747,1984.

26. Shellito, J., Murphy, S., and Warner, N. Flow cytometry analysis of lung cells from normal and acid-treated rabbits. Am. Rev. Respir. Dis. 124,333,1981.

27. Steinkamp, J.A., Hansen, K.M., Wilson, J.S., and Salzman, G.C. Flow-system analysis of exfoliated pulmonary cells: Results of initial characterization studies in hamsters. Natl. Tech. Inform. Ser. CONF-760927,264,1977.

28. Steinman, R.M., Gutchinov, B., Witmer, M.D., and Nussenzweig, M.C. Dendritic cells are the principal stimulators of the primary mixed leukocyte reaction in mice. J. Exp. Med. $157,613,1983$.

29. Thorell, B. Flow cytometric analysis of cellular endogenous fluorescence simultaneously with emission from exogenous fluorochromes, light scatter, and absorption. Cytometry 2,39,1981.

30. Toews, G.B., Vial, W.C., Dunn, M.M., Guzzetta, P., Nunez, G., Stastny, P., and Lipscomb, M.F. The accessory cell function of human alveolar macrophages in specific $\mathrm{T}$ cell proliferation. $\mathrm{J}$. Immunol. 132,181,1984.

31. Van Voorhis, W.C., Hair, L.S., Steinman, R.M., and Kaplan, G. Human dendritic cells. Enrichment and characterization from peripheral blood. J. Exp. Med. 155,1172,1982.

32. Venet, A., Hence, A.J., Saltini, C., Robinson, B.W.S., and Crystal, R.G. Enhanced alveolar macrophage-mediated antigen induced T lymphocyte proliferation in sarcoidosis. J. Clin. Invest. $75,293,1985$.

33. Weissler, J.C., Lyons, C.R., Lipscomb, M.F., and Toews, G.B. Human pulmonary macrophages. Functional comparison of cells obtained from whole lung and by bronchoalveolar lavage. Am. Rev. Respir. Dis. 133,473,1986.

34. Yam, L.T., Li, C.Y., and Crosby, W.H. Cytochemical identification of monocytes and granulocytes. Am. J. Clin. Pathol. $55,283,1971$. 